\title{
Influence of extraction process on antioxidant activity and rutin content in Physalis peruviana calyces extract
}

\author{
Maria Isabel Cardona ${ }^{1}$, Reina Marcela Toro ${ }^{1}$, Geison M. Costa ${ }^{2}$, Luis Fernando Ospina ${ }^{1}$, Leonardo Castellanos ${ }^{3}$, \\ Freddy A. Ramos ${ }^{3}$, Diana Marcela Aragón ${ }^{1 *}$ \\ ${ }^{1}$ Departamento de Farmacia, Universidad Nacional de Colombia, Bogotá D.C., Colombia. ${ }^{2}$ Departamento de Química, Pontificia Universidad Javeriana, \\ Bogotá D.C., Colombia. ${ }^{3}$ Departamento de Química, Universidad Nacional de Colombia, Bogotá D.C., Colombia.
}

\section{ARTICLE INFO}

Article history:

Received on: 18/07/2016

Accepted on: 03/10/2016

Available online: 30/06/2017

Key words:

Physalis peruviana,

antioxidant activity, rutin,

DPPH, HPLC-DAD

\begin{abstract}
Physalis peruviana is an exotic fruit highly valued for its bioactive compounds. This work evaluates the effect of some variables of the extraction process of $P$. peruviana calyces extract (considered waste material) on total phenolic content, rutin content, and in vitro antioxidant activity of the extracts obtained. First, the influence of certain factors of the extraction process on the above mentioned response variables were analyzed. The response variables were then evaluated using in vitro assays such as NO (nitric oxide) and DPPH (1,1-diphenyl-2picrylhydrazyl) uptake for antioxidant activity; the Folin-Ciocalteu method for total phenolic content; and the external standard method by HPLC-DAD for quantification of rutin. The results showed that the optimal conditions needed to obtain the best results for the response variables evaluated are the use of ethanol $70 \%$ as extraction solvent, and a percolation time of 72 hours, these being the factors that positively influenced the results.
\end{abstract}

\section{INTRODUCTION}

In recent decades, due to the large amount of research on phytochemistry and pharmacognosy, natural products from plant sources have gained particular importance in the treatment of different kinds of diseases (Gilani and Rahman, 2005; Patwardhan, 2005; Petronilho et al., 2012; Newman and Cragg, 2016). Cape gooseberry (Physalis peruviana L., Solanaceae) is an abundant specie of the South American Andes. The vegetal is an herbaceous, semi-upright shrub that is known for its round, orange-colored fruit. This fruit is about two inches in diameter and its juicy pulp, which has a pleasant smell and taste, is enclosed in five-sepal calyx (Wills et al., 1984). This species has become of great importance in Colombia, the world's largest exported (Garzón, 2012), which is usually consumed fresh or in beverage preparation. However, the calyces are considered waste material after harvesting of the fruit. In this sense, investigations

* Corresponding Author

Email: dmaragonn @ unal.edu.co with this organ can contribute to better use of this plant material, giving higher added value to the species and its cultivation. Additionally, many medicinal properties have been attributed to $P$. peruviana in folk medicine, such as antispasmodic, diuretic, sedative, analgesic, antiseptic, and antidiabetic properties (Puente et al., 2011), and it is also used to treat malaria, asthma, hepatitis, dermatitis and rheumatism ( $\mathrm{Wu}$ et al., 2006). The calyces, in particular, are widely used in traditional medicine to treat cancer, infections, fever and inflammation (Puente et al., 2011). In recent years, phytochemical studies of $P$. peruviana have shown the presence of phenolic compounds in different organs of this plant, such as the fruits and calyces, which correlates with the high antioxidant capacity of the plant (Licodiedoff et al., 2013; Toro et al., 2014; Vilaplana et al., 2014; Bravo et al., 2015). Different extraction methods are widely used to obtain crude extracts from plant materials. However, there is no universal extraction protocol because each plant or metabolite requires specific extraction conditions for optimal recovery of compounds, especially those responsible for biological activities. Effects of extraction process are, therefore, essentials to maintain and even 
improve positive effects on health. The aim of this study was to determine the best extraction conditions for calyces of $P$. peruviana, in order to obtain the highest rutin and total phenol contents, and better antioxidant capacity.

\section{MATERIALS AND METHODS}

\section{Plant material}

The calyces of Physalis peruviana L. were collected in the region of Granada Cundinamarca (2450 masl), on March, 2013. The fresh calyces were dried in an oven drying at a temperature of $40^{\circ} \mathrm{C}$ until constant weight, and ground in a knife mill. One specimen was stored in the Herbarium of the National University of Colombia (COL 512200).

\section{Materials}

Quercetin-3-O-rutinoside (rutin), 2,2-diphenyl-1picrylhydrazyl (DPPH), Folin-Ciocalteau phenol reagent, ascorbic acid and gallic acid were purchased from Sigma-Aldrich ${ }^{\circledR}$ (St. Louis, MO, USA); sodium carbonate $\left(\mathrm{Na}_{2} \mathrm{CO}_{3}\right)$, and methanol HPLC were supplied by J.T Baker ${ }^{\circledR}$ (Trinidad, Tobago) andacetic acid was obtained from Scharlau ${ }^{\circledR}$ (Sentmenat, Spain).

\section{Preparation of extracts}

For the extraction process, percolation with ethanol $(10: 150, \mathrm{~m} / \mathrm{v})$ was selected as the extraction method. The variables considered were the concentration of the extraction solvent (96 and $70 \%$ ethanol), the percolation time (48 and 72 hours), and the presence-absence of light..The number of tests and variations in combination were based of the experimental design suggested by statistical software $\mathrm{R}$ (Table 1). After extraction of the plant material, the extracts were evaporated to dryness in reduced pressure at $35^{\circ} \mathrm{C}$.

Table 1: Experimental design matrix for preparation of $P$. peruviana calyces extracts.

\begin{tabular}{cccc}
\hline Experiment & $\begin{array}{c}\text { Duration of } \\
\text { extraction } \\
\text { (hours) }\end{array}$ & $\begin{array}{c}\text { Presence of } \\
\text { light during } \\
\text { extraction }\end{array}$ & $\begin{array}{c}\text { Extraction } \\
\text { solvent }\end{array}$ \\
\hline 1 & 72 & No & EtOH 70\% \\
2 & 48 & Yes & EtOH 96\% \\
3 & 48 & No & EtOH 96\% \\
4 & 48 & Yes & EtOH 70\% \\
5 & 72 & Yes & EtOH 70\% \\
6 & 72 & No & EtOH 70\% \\
7 & 72 & No & EtOH 96\% \\
8 & 48 & No & EtOH 70\% \\
9 & 72 & No & EtOH 96\% \\
10 & 72 & Yes & EtOH 96\% \\
11 & 48 & No & EtOH 70\% \\
12 & 48 & Yes & EtOH 96\% \\
\hline
\end{tabular}

\section{Determination of Total Phenolic Content (TCP)}

The TPC in the extracts was determined according to the methodology previously described by Kappel and co-workers (2008), with slight modifications. Briefly, a $100 \mu \mathrm{L}$ aliquot of extracts was assayed with $100 \mu \mathrm{L}$ of Folin-Ciocalteu $2 \mathrm{~N}$ reagent and $200 \mu \mathrm{L}$ of sodium carbonate $(7.5 \%)$. The resulting solution was vortex-mixed and diluted with distilled water to obtain a final volume of $2 \mathrm{ml}$. After 2 hours, the absorption was measured at 726 $\mathrm{nm}$. Gallic acid was used as standard and the total phenolic content was expressed as $\mathrm{mg}$ of gallic acid/g of extract (Kappel et al., 2008).

\section{HPLC analysis}

A Shimadzu ${ }^{\circledR}$ system (Shimadzu, Tokyo, Japan), consisting of a LC-6AD binary pump, SPD-M20A diode array detector (DAD), SIL-20A HT auto-sampler, DGU- 20As in-line degasser, and software LCsolution ${ }^{\circledR}$ were used. The injections (10 $\mu \mathrm{L})$ were carried out on a Phenomenex C-18 $10 \mu \mathrm{m}(150 \times 3.9$ $\mathrm{mm}$ ) column conditioned in a Shimadzu ${ }^{\circledR}$ CTO-20A column oven equilibrated at $35^{\circ} \mathrm{C}$, with detection at $350 \mathrm{~nm}$. For the development of the method, different solvent systems were assayed in gradient conditions using methanol, acetonitrile and acidified water $(0.5 \%$ acetic acid $)$, at $1.0 \mathrm{ml} / \mathrm{min}$. The best gradient was chosen: acidified methanol $(0.5 \%$ acetic acid) (A) with acidified water $(0.5 \%$ acetic acid) $(\mathrm{B})$ as follows: $10-50 \% \mathrm{~A}(0-$ $5 \mathrm{~min}), 50 \% \mathrm{~A}(5-10 \mathrm{~min}), 50-80 \% \mathrm{~A}(10-15 \mathrm{~min})$ and $80 \%$ A $(15-25 \mathrm{~min})$.

Individual injections of ethanolic extract solution (1.0 $\mathrm{mg} / \mathrm{ml}$ ) were performed before all the measurements, to assess the suitability parameters, including retention time $\left(t_{R}\right)$, resolution $(R)$ between rutin and neighboring peak, capacity factor (k') and selectivity factor $(\alpha)$. Dried extracts were diluted at $1.0 \mathrm{mg} / \mathrm{ml}$ in methanol. The solution was filtered through a $0.45 \mathrm{~mm}$ membrane prior to injection into the HPLC system.

The validation of analytical procedures was performed according to the ICH guidelines (ICH, 2005).Validated parameters were specificity, linearity, accuracy, precision (repeatability and intermediate precision), limit of quantification (LOQ) and limit of detection (LOD).

\section{DPPH Test}

The free radical scavenging activities of the extracts were measured by the DPPH method. The DPPH radical (DPPH•) solution $(33 \mu \mathrm{g} / \mathrm{ml})$ was prepared in methanol. A volume of $30 \mu \mathrm{L}$ of the DPPH solution was mixed with $70 \mu \mathrm{L}$ of the tested extracts. The mixture was mixed and incubated at room temperature in the dark for $30 \mathrm{~min}$. The absorbance of the samples was recorded at $570 \mathrm{~nm}$ against a blank, and the results were expressed as \% of remaining DPPH• (Mandade et al., 2011).

\section{Nitric oxide Test}

A volume of $10 \mu \mathrm{L}$ of prediluted ethanolic extracts was incubated with $1 \mathrm{ml}$ of sodium nitroprusside (NANP) 5Mmfor 2 hours. A standard curve was obtained using gallic acid solution and rutin solution. A $100 \mu \mathrm{L}$ aliquot of the tubes containing the samples was placed in the wells of the plate containing the distinct calibration curve solutions.1 $\mathrm{ml}$ of phosphate buffer solution (PBS) was used as blank, and $1 \mathrm{ml}$ of NANP was used as control for maximum NO release. In addition $1 \mathrm{ml}$ ethanol was used as vehicle, to dissolve the sample. Next, $100 \mu \mathrm{L}$ of freshly prepared Griess reagent was added to each of the wells and mixed for five 
minutes. The absorbance of the samples was measured at $550 \mathrm{~nm}$. The results were also expressed as \% uptake of nitric oxide (Rop et al., 2012).

\section{Statistical Analysis}

All determinations were carried out in triplicate. The influence of the extraction conditions was evaluated using Principal Component Analysis (PCA). Statistical analysis was performed using the " $\mathrm{R}$ " software.

\section{RESULTS AND DISCUSSION}

The HPLC method developed for rutin quantification proved to be linear in the range of $0.156-40.0 \mu \mathrm{g} / \mathrm{ml}$. The correlation coefficient $\left(\mathrm{r}^{2}\right)$ was 0.9995 . The limit of quantification was determined experimentally as $0.1562 \mu \mathrm{g} / \mathrm{ml}$ and the detection limit was $0.0078 \mu \mathrm{g} / \mathrm{ml}$. The results obtained for the precision and accuracy of the method are shown in Table 2.

Table 2: Precision and accuracy of the HPLC-DAD method for rutin quantification in P. peruviana calyces.

\begin{tabular}{|c|c|c|c|c|c|c|c|}
\hline \multirow[b]{2}{*}{ 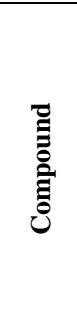 } & \multicolumn{2}{|c|}{ Repeatability } & \multicolumn{2}{|c|}{$\begin{array}{l}\text { Intermediate } \\
\text { precision }\end{array}$} & \multicolumn{3}{|c|}{ Accuracy } \\
\hline & 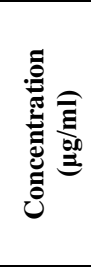 & 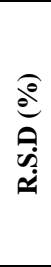 & & $\begin{array}{l}\widehat{\theta} \\
\hat{\theta} \\
\dot{0} \\
\ddot{0}\end{array}$ & 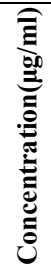 & 氖 & $\underset{\dot{\phi}}{\dot{0}}$ \\
\hline Rutin & $\begin{array}{c}40 \\
2.5 \\
0.15\end{array}$ & $\begin{array}{l}1.6 \\
1.3 \\
0.2\end{array}$ & 2.5 & 2.8 & 2.5 & 102.2 & 0.3 \\
\hline
\end{tabular}

R.S.D.: Relative Standard Deviation

The total phenolic contents observed in this study for the 12 extracts prepared from the calyces (ranged from $11.99 \pm 0.04$ to $20.86 \pm 0.36 \mathrm{mg}$ gallic acid/g of extract) are lower than those previously reported for $P$. peruviana leaves (Wu et al., 2006). In that work, the authors found that the total phenolic content, according to the extraction solvent used, was higher with supercritical $\mathrm{CO}_{2}$ and ethanol $95 \%$, and lower with boiling water (90.80, 88.81,19.64 G.A./g extract, respectively).

Antioxidant activity was evaluated using two different in vitro assays; uptake of nitric oxide, a biologically important reactive oxygen species, and $\mathrm{DPPH} \bullet$ scavenging activity, a mechanistic test. The estimated values of $\mathrm{DPPH} \bullet$ scavenging activity ranged from $25.4 \pm 0.5$ to $60.2 \pm 1.2 \%$, while nitric oxide uptake activity ranged from $7.1 \pm 1.7$ to $68.7 \pm 1.1$, as described in Table 3. A recent study about the effects of cultivar and harvest time on fruits of $P$. peruviana reported DPPH • scavenging activity range from 18.47 to $26.56 \%$ inhibition (Bravo et al., 2015). Vilaplana and co-workers (2014) reported higher DPPH• scavenging activity for calyces than for fruits of $P$. peruviana (4.49 mmol and 1.60 Trolox/100 g of extract, respectively). On the other hand, although there is no reported data on nitric oxide uptake specifically for $P$. peruviana calyces, a previous work carried out with an ethanolic extract of the fruits found nitric oxide uptake activity of $35.02 \%$ (Rop et al., 2012), close to that obtained in the present study. Since previous investigations have reported that rutin is the major compound of calyces of $P$. peruviana, and is responsible of its antioxidant activity (Toro et al., 2014; Vilaplana et al., 2014), it was important in this work to develop an HPLCDAD for rutin quantification in $P$. peruviana calyces. The values of rutin ranged from $5.12 \pm 0.03$ to $13.25 \pm 0.02 \mu \mathrm{g}$ rutin $/ \mathrm{mg}$ extract (Table 3). These values are higher than those previously reported $(1.47 \mu \mathrm{g}$ rutin/mg extract) for methanolic extracts of calyces of $P$. peruviana (Vilaplana et al., 2014).

Table 3: Yield, antioxidant activity, total phenolic content and rutin content of ethanolic extracts of calyces of $P$. peruviana.

\begin{tabular}{|c|c|c|c|c|c|}
\hline 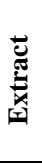 & 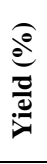 & $\begin{array}{c}\text { DPPH• } \\
\text { scavenging } \\
(\%)\end{array}$ & $\begin{array}{c}\text { Nitric } \\
\text { oxide } \\
\text { uptake } \\
(\%)\end{array}$ & $\begin{array}{c}\text { Total } \\
\text { phenolic } \\
\text { content } \\
\text { (mg G.A./g } \\
\text { extract) }\end{array}$ & $\begin{array}{c}\text { Rutin } \\
\text { content } \\
\text { ( } \mu \text { g/mg } \\
\text { extract) }\end{array}$ \\
\hline 1 & 22 & $45.7 \pm 2.8$ & $47.7 \pm 1.5$ & $20.86 \pm 0.3$ & $13.25 \pm 0.0$ \\
\hline 2 & 13 & $30.0 \pm 2.5$ & $23.2 \pm 0.6$ & $16.85 \pm 0.1$ & $6.42 \pm 0.0$ \\
\hline 3 & 13 & $29.8 \pm 1.5$ & $21.4 \pm 1.6$ & $17.14 \pm 0.2$ & $5.74 \pm 0.1$ \\
\hline 4 & 20 & $60.2 \pm 1.2$ & $27.9 \pm 1.7$ & $17.15 \pm 0.3$ & $5.88 \pm 0.0$ \\
\hline 5 & 23 & $45.8 \pm 2.0$ & $46.9 \pm 0.4$ & $20.44 \pm 0.3$ & $6.42 \pm 0.1$ \\
\hline 6 & 23 & $36.8 \pm 3.7$ & $51.4 \pm 1.4$ & $18.66 \pm 0.5$ & $8.33 \pm 0.2$ \\
\hline 7 & 15 & $30.1 \pm 1.5$ & $58.4 \pm 1.3$ & $16.80 \pm 0.1$ & $6.52 \pm 0.0$ \\
\hline 8 & 20 & $44.9 \pm 0.8$ & $37.7 \pm 1.7$ & $14.51 \pm 0.2$ & $13.00 \pm 0.0$ \\
\hline 9 & 12 & $26.7 \pm 0.5$ & $63.3 \pm 1.3$ & $17.15 \pm 0.2$ & $7.41 \pm 0.0$ \\
\hline 10 & 12 & $25.4 \pm 0.5$ & $68.7 \pm 1.1$ & $16.37 \pm 0.3$ & $5.12 \pm 0.0$ \\
\hline 11 & 21 & $46.4 \pm 3.0$ & $7.1 \pm 1.7$ & $11.99 \pm 0.0$ & $10.81 \pm 0.0$ \\
\hline 12 & 14 & $32.1 \pm 2.0$ & $9.2 \pm 0.1$ & $15.52 \pm 0.1$ & $5.72 \pm 0.0$ \\
\hline
\end{tabular}

According to the PCA statistical analysis (Figure 1), the first group (cluster 1, which includes extracts 9, 7, 2, 3 and 12) contained the extracts with the lowest levels of rutin $(5.12 \mu \mathrm{g} / \mathrm{mg}$ extract), DPPH• scavenging (25.4\%) and extractive yield (15\%). This cluster is composed wholly of extracts obtained with $96 \%$ ethanol.

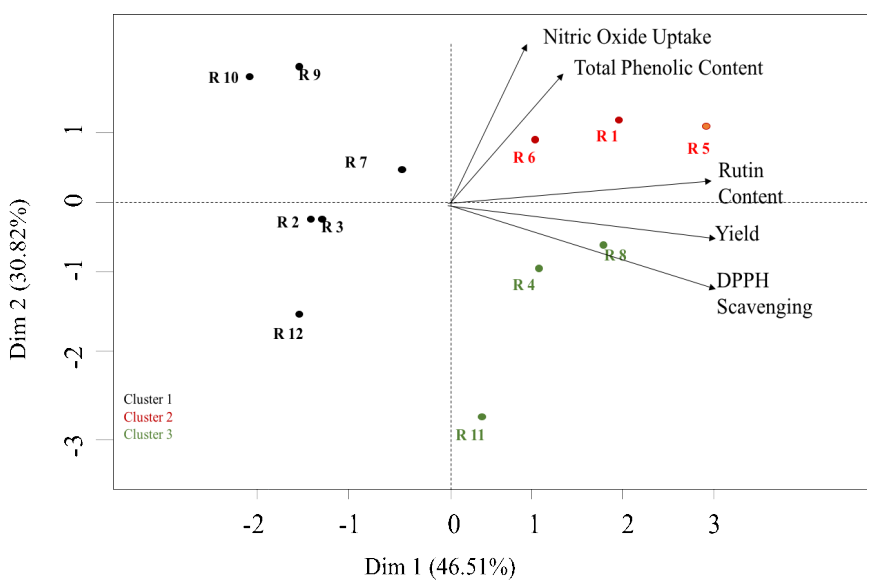

Fig. 1: Graphical illustration of the Principal Component Analysis of the extractive conditions on the yield,antioxidant activity total phenolic and rutin content of $P$. peruviana calyces extracts.

The second group (cluster 2: extracts 6,1 and 5) includes the extracts with the highest content of total phenols $(20.86 \mathrm{mg}$ gallic acid/g) and rutin (13.25 $\mu \mathrm{g} / \mathrm{mg}$ extract), all of which were 
obtained with $70 \%$ ethanol and 72 hours percolation time. Finally, cluster 3 (extracts 4, 8 and 11) is characterized by extracts with high DPPH• scavenging uptake. None of the extraction conditions was found to have a significant influence, and none of them was found to be a common factor among individuals belonging to this cluster (Figure 1).

According to the results of the present work, the choice of extraction solvent was a determining factor in the extraction process. This fact could be explained by the polarity of $70 \%$ ethanol, which is most similar to the polarity of the compounds present in the extracts of calyces of $P$. peruviana. This characteristic reflected the higher antioxidant activity, total phenolic content and rutin content, according to previous reports that indicate that antioxidant activity is dependent on the solvent used in the extraction process (Ghafoori et al., 2014).

Similar results have previously been reported, indicating the efficiency of ethanol (50-60\%) in the extraction of rutin and total phenolic content (Kim et al., 2005; Soto et al., 2014). The results of this study also agree with those of other studies, which determined that the extraction solvent is the key to success in the extraction of rutin from Hibiscus mutabilis, according to the principle of "like dissolves like." In this study, best results were achieved with the higher polarity solvents (Xie et al., 2011). A percolation time of 72 hours was the one that obtained the highest results for total phenolic content and rutin content. These results are consistent with previous studies that describe the influence of extraction time on the total phenolic content and the rutin content obtained from coffee grounds (Mussatto et al., 2011). The presence of light was not a determining factor for any of the response variables evaluated. Regarding to the possible relationship between the studied variables, these are graphically illustrated in the circle of correlations, where the most closely correlated variables show a slight angle between them (Figure 2).

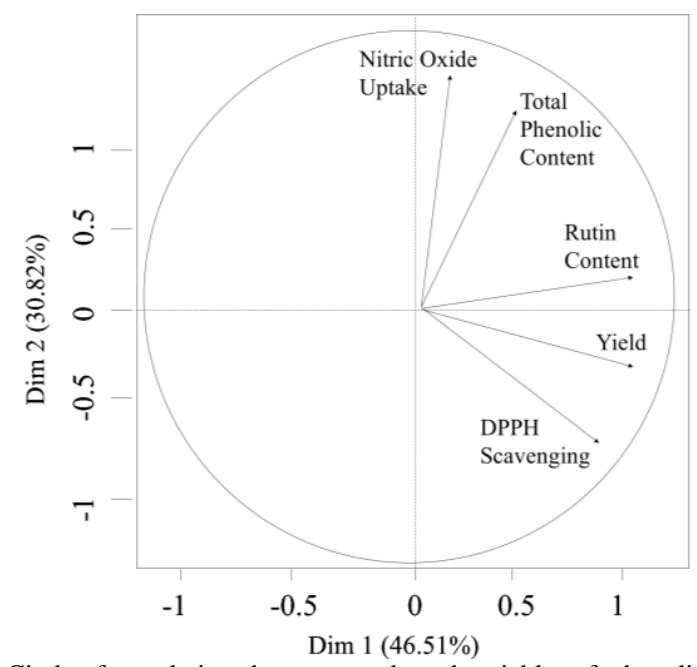

Fig. 2: Circle of correlations between evaluated variables of ethanolic extracts of calyces of $P$. peruviana.

About the results observed in Figure 2, a very good correlation was found between nitric oxide uptake and total phenolic content. These data are in accordance with the results reported previously for ethanolic extracts of $P$. peruviana fruits, which found a high correlation of $r^{2}=0.9232$ between these two variables (Rop et al., 2012).

This suggests that the phenolic compounds of the extract of calyces of $P$. peruviana are responsible, at least in part, for the antioxidant activity evaluated by the nitric oxide uptake assay. A slight correlation was also found between rutin content and $\mathrm{DPPH} \cdot$ scavenging activity. This correlation is expected, taking into account works that report high DPPH• scavenging activity (90.4\%) by low rutin concentration $(0.05 \mathrm{mg} / \mathrm{ml})$ (Yang et al., 2008). These results suggested that the antioxidant activity of rutin can be attributed to its ability to donate hydrogen to stabilize DPPH radicals.

\section{CONCLUSIONS}

Considering the statistical analysis, the optimal extraction conditions to achieve the best results in terms of yield, antioxidant activity, total phenols and rutin content are: $70 \%$ ethanol as extraction solvent, and a total percolation time of 72 hours. Light is not a determining factor. Also, a correlation was observed between total phenol content and nitric oxide uptake, while rutin content was correlated to $\mathrm{DPPH} \bullet$ scavenging activity.

\section{ACKNOWLEDGEMENT}

The authors are very grateful for the financial support provided by the Fondo Nacional de Financiamiento para la Ciencia, la Tecnología y la Innovación, Francisco José de Caldas, contract No. 657-2014. The authors declare that they have no conflict of interest.

\section{REFERENCES}

Bravo K, Sepulveda-Ortega S, Lara-Guzman O, NavasArboleda AA, Osorio E. Influence of cultivar and ripening time on bioactive compounds and antioxidant properties in Cape gooseberry (Physalis peruviana L.). J Sci Food Agric, 2015; 95:1562-1569.

Garzón G. 2012. Anotación del transcriptoma foliar de la uchuva (Physalis peruviana L.): fruta promisoria de la familia solanaceae. Master Thesis. Pontificia Universidad Javeriana. Bogotá, Colombia.

Ghafoori H, Sariri R, Naghavi MR.Study of effect of extraction conditions on the biochemical composition and antioxidant activity of Artemisia absinthium by HPLC and TLC. J Liq Chromatogr R T, 2014; 37:1558-1567.

Gilani AH, Rahman AU. Trends in ethnopharmacology. J Ethnopharmacol, 2005; 100:43-49.

ICH (International Conference on Harmonization).2005. Validation of Analytical Procedures: Text and Methodology - Q2(R1) IFPMA, London.

Kappel V, Costa GM, Scola G, Silva F, Landell M, Valente P, Souza D, Vanz D, Reginatto FH, Moreira JC.Phenolic Content and Antioxidant and Antimicrobial Properties of Fruits of Capsicum baccatum L. var. pendulum at Different Maturity Stages. J Med Food, 2008; 11:267274.

Kim K, Lee K, Kim D, Park H, Kwon I, Lee H. Optimal recovery of high-purity rutin crystals from the whole plant of Fagopyrum esculentum Moench (buckwheat) by extraction, fractionation, and recrystallization. Bioresource Technol, 2005; 96:1709-1712. 
Licodiedoff S, Koslowski L,Ribani R.Flavonols and antioxidant activity of Physalis peruviana L.fruit at two maturity stages. Acta SciTechnol, 2013; 35:393-399.

Mandade R, Sreenivas S, Choudhury A.Radical Scavenging and antioxidant activity of Carthamustinctorius extracts. Free Radical Antiox, 2011; 1:87-93.

Mussatto S, Ballesteros L, Martins S, Teixeira J.Extraction of antioxidant phenolic compounds from spent coffee grounds. Sep Purif Technol, 2011; 83:173 -179.

Newman DJ, Cragg GM. Natural Products as Sources of New Drugs from 1981 to 2014. JNatProd, 2016; 79:629-661.

Patwardhan B. Ethnopharmacology and drug discovery. J Ethnopharmacol, 2005; 100:50-52.

Petronilho S, Maraschin M, Coimbra M, Rocha S.In vitro and in vivo studies of natural products: A challenge for their valuation. The case study of chamomile (Matricaria recutita L). Ind Crop Prod, 2012; 40: 1 12 .

Puente L, Pinto-Muñoz C, Castro E, Cortés M.Physalis peruviana Linnaeus, the multiple properties of a highly functional fruit: A review. Food Res Int, 2011; 44:1733-1740.

Rop O, MLcek J, Jurikova T, Valsikova M. (2012).Bioactive content and antioxidant capacity of Cape gooseberry fruit. Cent. Eur. J. Biol, 2012; 7:672-679.

Soto C, Caballero E, Pérez E, Zúñiga ME.Effect of extraction conditions on total phenolic content and antioxidant capacity of pretreated wild Peumus boldus leaves from Chile. Food Bioprod Process, 2014; 92:328-333.
Toro R, Aragón D, Ospina L, Ramos F, Castellanos L. Phytochemical Analysis, Antioxidant and Anti-Inflammatory Activity of Calyces from Physalis peruviana. Nat Prod Commun, 2014, 9:1-2.

Vilaplana A, Baena N, Villaño D, Speisky H, García-Viguera C, Moreno D.Evaluation of Latin-American fruits rich in phytochemicals with biological effects. J Funct Foods, 2014; 7:599-608.

Wills R, Lee T, Mcglasson W, Hall E.Fisiología y manipulación de /hitas y hortalizas pos/-recolección. Acribia, 1984; 1:3-41.

Wu S, Tsai J,Chang S, Lin D, Wang S, Huang S, Ng L.Supercritical carbon dioxide extract exhibits enhanced antioxidant and anti-inflammatory activities of Physalis peruviana. J Ethnopharmacol, 2006; 108:407-413.

Xie J, Shi L, Zhu X, Wnag P, Zhao Y, Su W.Mechanochemicalassisted efficient extraction of rutin from Hibiscus mutabilis L. Innov Food Sci Emerg, 2011; 12:146-152.

Yang J, Guo J, Yuan J.In vitro antioxidant properties of rutin. LWT-Food Sci Technol, 2008; 41:1060-1066.

\section{How to cite this article:}

Cardona MI, Toro RM, Costa GM, Ospina LF, Castellanos L, Ramos F, Aragón DM. Influence of extraction process on antioxidant activity and rutin content in Physalis peruviana calyces extract. J App Pharm Sci, 2017; 7 (06): 164-168. 